\title{
Perilaku Beresiko Pada Lansia “Endong-Endong" Di Pasar Induk Sayur Dan Buah Giwangan Yogyakarta: Strategi Penguatan Buruh Gendong Melalui Pos Upaya Kesehatan Kerja
}

\section{KONTEKS MASALAH}

Terciptanya kehidupan yang sehat dan meningkatkan kesejahteraan untuk semua usia adalah salah satu fokus SDGs. Namun, hal ini belum terlaksana secara menyeluruh di Indonesia. Endong-endong, atau wanita yang berprofesi
mengangkut barang di pasar dengan menggendong menggunakan kain jarik.

menggunakan kain jarik.
Sejumlah 60 orang diantaranya merupakan lansia, dimana mereka setiap harinya menggendong buah dan sayu seberat 25-98 kg dalam satu kali angkut dengan frekuensi 15 kali atau lebih. Mereka bekerja tanpa memperhatikan faktor ergonomis seperti berat beban maksimal untuk wanita, frekuensi angkat maksimal dalam sehari kerja, teknik mengangkat beban, waktu kerja, dan tidak memperhatikan
jarak tempuh mengangkut beban.

Tidak menentunya jam kerja juga mengakibat-kan buruh gendong bekerja melebihi standar jam kerja maksi-mal, yang memperburuk statustus kesehatannya.

Image

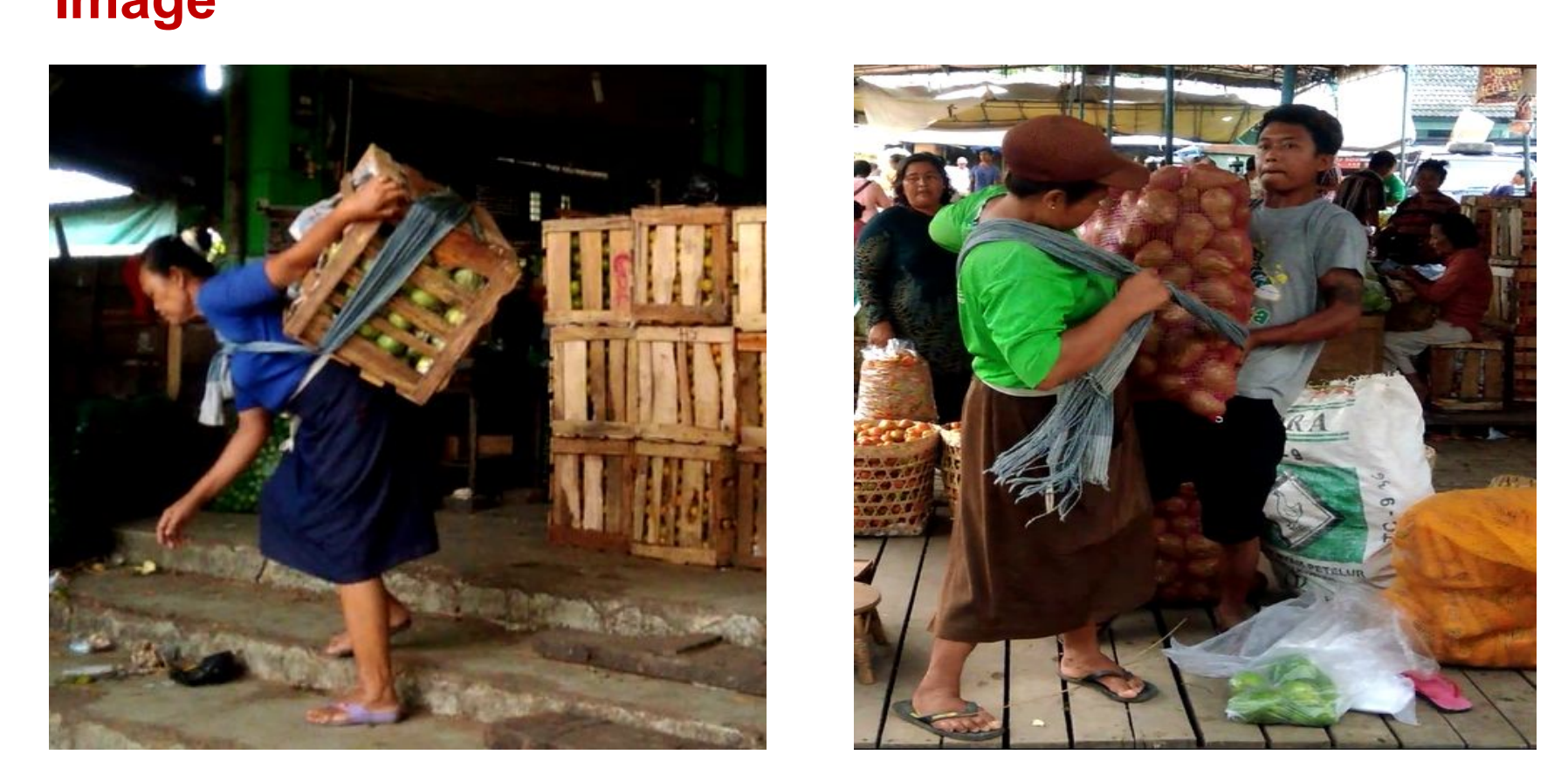

TEMUAN MASALAH KESEHATAN

Perilaku tersebut dapat menimbulkan masalah kesehatan terutama PAK (penyakit akibat kerja) yaitu nyeri pada sistem nyeri pada tangan, lutut, dan kaki. Masalah yang sering dialami lansia endong-endong adalah keluhan low back pain (nyeri punggung bawah)
Kondisi lingkungan pasar yang kerap kali licin akibat adanya genangan dari aktivitas pedagang maupun hujan menjadi salah satu faktor terjadinya kecelakaan kerja sepert terpeleset dan terjatuh. Selain itu, kelelahan akibat kerja juga akan meningkatkan risiko terjadinya kecelakaan akibat kerja. Risiko masalah kesehatan ini semakin tinggi terlebih pada lansia mengingat bahwa lansia wanita memiliki daya tahan tubuh yang lebih rentan dibandingkan dengan wanita

produktif.
Disamping itu, jam kerja yang tidak menentu dan buruh gendong jang akibanya buruh gendo 8 jam Dantaranya men-galami sakit dalam satu bulan tong, $75 \%$ tersebut tentunya dapat menurunkan produk-tivitas buruh gendong yang secara luas akibatnya dapat berpengaruh pada jalannya perekonomian pasar

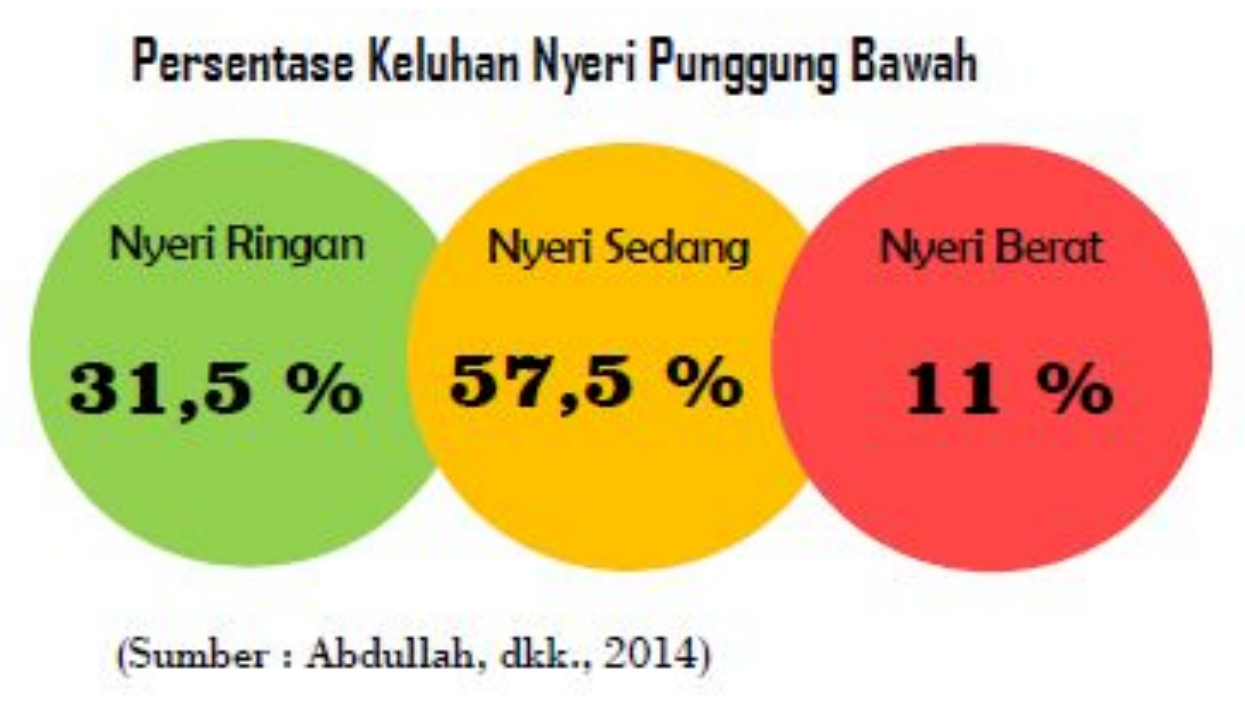

STRATEGI PENYELESAIAN MASALAH

Perilaku tersebut dapat menimbulkan masalah kesehatan erutama PAK (penyakit akibat kerja) yaitu nyeri pada sistem muskuloskeletal seperti otot-otot punggung, pinggang, juga
nyeri pada tangan, lutut, dan kaki. Masalah yang sering dialami ansia endong-endong adalah keluhan low back pain (nyer punggung bawah).

(n) meningkatkan kesehatan buruh gendong dan dilakukan dengan upaya kesehatan kerja yang tersedia tentunya berlandaskan atas prinsip pencegahan teriadinya penyakit dan kecelakaan akibat kerja untuk meningkatkan - pengetahuan dan perubahan perilaku buruh gendong sehingga dapat mengurangi terjadinya penyakit dan kecelakaaan yang diakibatkan karena bekerja.

Agar hal tersebut dapat berjalan secara berkelanjutan, maka strategi yang dilakukan yaitu dengan memanfaatkan sumberdaya yang sudah dimiliki oleh buruh gendong dengan Dinu oleh sumberdaya dan kebijakan dari BERBAGAl Dinas yang terkait. Yaitu Dinas Kesehatan dan Dinas Pong dan Perindustian.

Poh dimiliki oleh buruh gendong sama yang dapat diarahkan una kesehatan bersumber dengan baik dibawah naungan Yayasan Anisa Swasti (YASANTI).

Salah satu upaya kesehatan bersumber masyarakat yang dapat diterapkan pada buruh gendong adalah Pos Usaha Kesehatan Kerja (Pos UKK). Yang merupakan upaya penanggulangan masalah kesehatan kerja pada pekerja rormal yang direkomendasikan oleh Kementrian Kesehatan. Didalam Pos UKK, Lerdapat upaya-upaya pencegahan penyakit dan kecelakaan keja setta upaya pengobatan dan beroperasi di Pasar Giwangan sebelumnya diberikan pelatihan upaya pencegahan pengobatan, dan terapi sebagai kader kemudian keahlian yang didapat tersebut diterapkan pada anggota kelompok Pos UKK Buruh Gendong.

\section{REKOMENDASI}

1. Mendirikan Pos Usaha Kesehatan Kerja di Pasar Induk Giwangan dengan langkah-langkah

a. Mengadakan pelatihan keterampilan pencegahan penyakit

b. Mediakan fasilitas /tempat operasional Pos UKK di Pasar c. Mengadakan

pelaksanaan Pos UKK

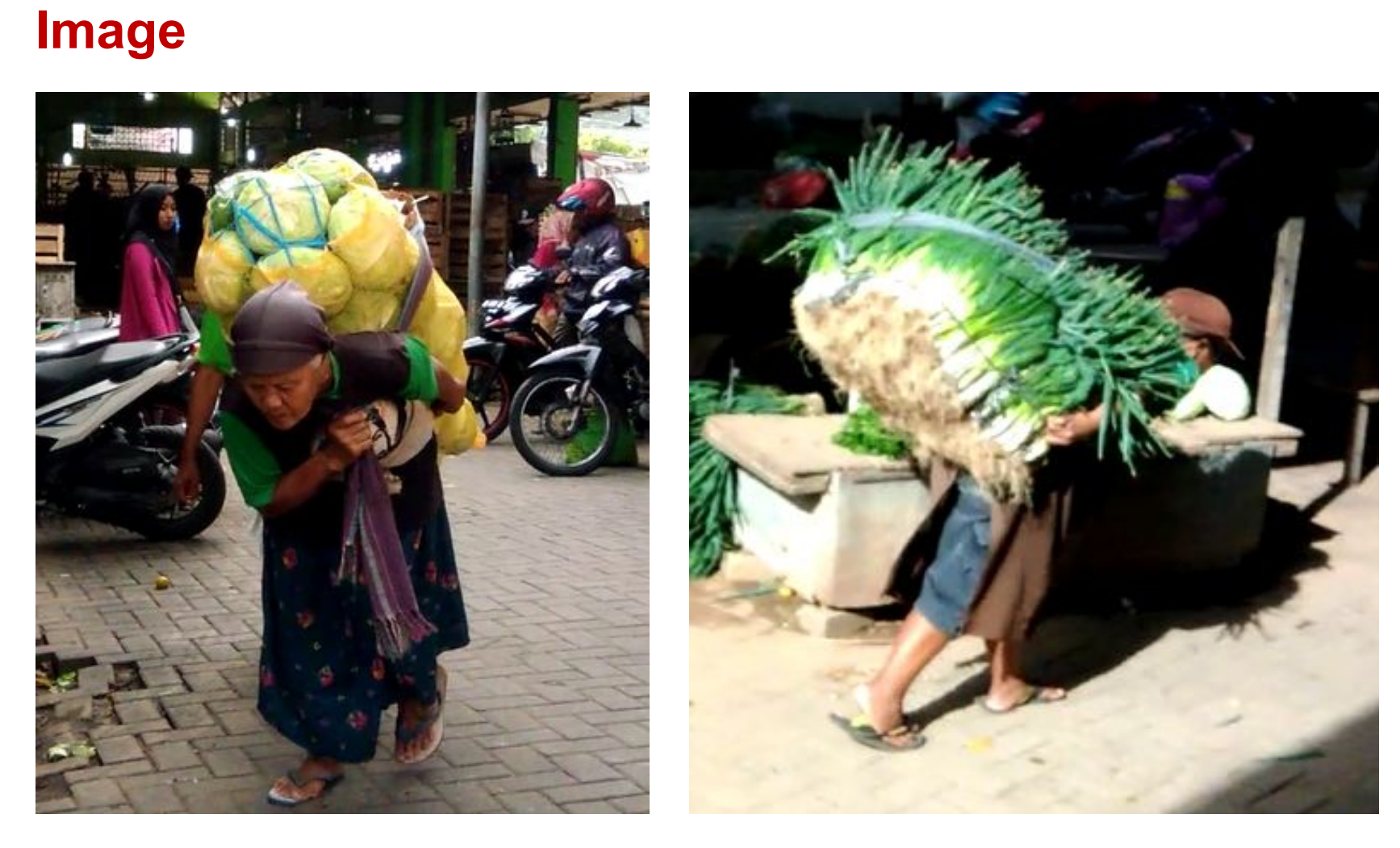

2. Membuat peraturan yang mewajibkan agar semua buruh gendong di Pasar Giwangan tegabung didalam Pos UKK buruh gendong

3. Mengadakan kerjasama lintas sektor dengan Dinas Perdagangan dan Perindustrian untuk melakukan monitoring

BIBLIOGRAPHY

Kementrian Kesehatan Rl. (2016). Info Data Dan Informasi Kesehatan Lansia.
Kementrian Kesehatan RI. Jakarta Kemementrian Kesehatan RI. Jakarta
Republik Indatatan Repubibik Indonesia. (2016). Peraturan Menteri Kesehatan
Ko. 100 Tahun 2015 Tentang Pos Upaya Kesehatan Kerja Terintegrasi. Berita Negara Republik Indonesia. No.78
und, F., Affers,L, Santana, F; (2016). Towards An Inclusive Occu-pational Heath

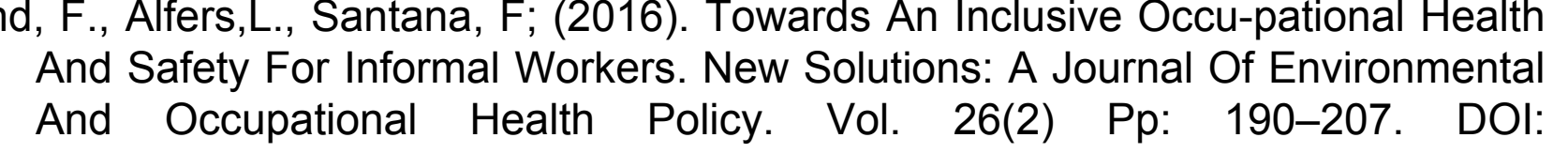
Rosanti, E., Andarini, Y.V., (2017). Program Pendampingan Pemben-tukan Pos
Upaya Kesehatan Keria (Ukk) Pada Petani Di Desa De-mangan Ponorogo. Upaya Kesehatan Keria (Ukk) Pada Petani Di Desa De-mangan Ponorogo
Jurnal Pemberdayaan Masyarakat, Vol. 2 No. 2 pp: 104-110, ISSN : 254111977

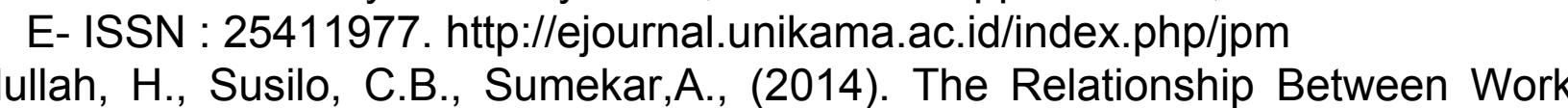
Attitude And The Heavy Load With Low Back Pain Int The Carrying Laborer In
The Traditional Market Beringhario Yogga-karta. Jurnal Kesehatan Masyarakat.Vol 07 No.02. pp: $285-292$
Riwi, S., Sari, V.K., (2015), Kontribusi Sistem Jasa Gendong Di Pasar Tradisional
Terhadap Upaya Penanggulangan Kemiskinan Me--lalui Sektor Informal. Journal of Rural and Development. Volume VI No. 1 pp: 43-58
Bartholomew, LK.et al. (2006). Planning Heaath Promotion Program. San Francisco:
John Wiley \& Sons, Inc. 